\title{
Renal progenitor cells modulated by angiotensin II receptor blocker (ARB) medication and differentiation towards podocytes in anti-thy1.1 nephritis
}

\author{
Di Wu ${ }^{1,2}$, Jiuxu Bai ${ }^{1,2}$, Shaoyuan $\mathrm{Cui}^{2}$, Bo Fu ${ }^{2}$, Zhiwei Yin $^{2}$, Guangyan Cai ${ }^{2}$, Xiangmei Chen ${ }^{1,2}$ \\ ${ }^{1}$ Medical School of Chinese PLA, Beijing 100853, China; ${ }^{2}$ Department of Nephrology, Chinese PLA General Hospital, Chinese PLA Institute of \\ Nephrology, State Key Laboratory of Kidney Diseases, National Clinical Research Center for Kidney Diseases, Beijing Key Laboratory of Kidney \\ Diseases, Beijing 100853, China \\ Contributions: (I) Conception and design: D Wu, X Chen; (II) Administrative support: X Chen; (III) Provision of study materials or patients: All \\ authors; (IV) Collection and assembly of data: All authors; (V) Data analysis and interpretation: D Wu; (VI) Manuscript writing: All authors; (VII) \\ Final approval of manuscript: All authors. \\ Correspondence to: Xiangmei Chen. Haidian District, Fuxing Road 28, Beijing 100853, China. Email: xmchen301@126.com.
}

\begin{abstract}
Background: Mesangial proliferative glomerulonephritis (MsPGN) is an epidemic disease with increasing occurrence. As important as mesangial cells, podocytes are key innate cells for MsPGN prognosis and recovery. Renal progenitor cells, located at the urinary pole (UP) of Bowman's capsule (BC), could alleviate kidney injury through their capacity to differentiate into podocytes.

Methods: Seventy-two male rats were categorized randomly into the sham $(n=24)$, untreated Thy-1 ( $n=24)$ and losartan-treated ( $\mathrm{n}=24)$ groups. We administered vehicle or losartan $(50 \mathrm{mg} / \mathrm{kg}$ by gavage) daily to treat rats with anti-thy1.1 nephritis, an ideal model to simulate human MsPGN. Two weeks after the intravenous injection of antibody, urinary protein and blood samples were analyzed, pathological changes were examined, the number of podocytes was determined, and renal progenitor cells were studied.

Results: Anti-thy1.1 nephritis was significantly alleviated after losartan treatment, as reported previously and as expected. Compared with the untreated Thy-1 group, the number of podocytes in the losartan group increased, and the area of renal progenitor cells significantly increased. The protein expression of components of the p-ERK pathway was determined during the development of renal progenitor cells differentiating into podocytes.

Conclusions: The data in this paper show the direct glomerular cell action of angiotensin II receptor blocker (ARB) treatment in improving outcomes in anti-thy1.1 nephritis. The positive effects of ARB medication on anti-thy1.1 nephritis were due to an increase in the number of renal epithelial progenitor cells (defined as PECs that expressed only stem cell markers without podocyte proteins).
\end{abstract}

Keywords: Anti-thy1.1 nephritis; podocyte repopulation; renal progenitor cells; parietal epithelial cell (PECs)

Submitted Oct 24, 2019. Accepted for publication Jan 10, 2020.

doi: $10.21037 /$ atm.2020.02.58

View this article at: http://dx.doi.org/10.21037/atm.2020.02.58

\section{Introduction}

Mesangial proliferative glomerulonephritis (MsPGN) is an epidemic disease worldwide (1-3). The main pathological change in MsPGN is the lesion of mesangial cells $(4,5)$. However, the depletion of podocytes in MsPGN is invariably recognized as the main cause of nephron loss, glomerulosclerosis and end-stage renal disease (ESRD), which are more serious (3,6-9).

Podocytes are highly specialized and terminally differentiated epithelial cells and are involved in many kinds of nephritis (10-14). They are irreversible and irreparable, as recognized before $(3,15-17)$. Recent studies 
reported that progenitor cells, localized at the renal parietal epithelium of Bowman's capsule (BC) (18-20), are able to potentially regenerate novel podocytes (19,21-30). Among the hierarchical subpopulations of parietal epithelial cells (PECs), renal progenitor cells, defined as cells that only express stem cell proteins and not podocyte markers, seem to be the most promising future therapeutic method for nephritis $(23,31)$. This subset of PECs shows the potential capacity to differentiate into a transitional state expressing both stem cells and podocyte markers $(32,33)$ and then into terminal podocytes at the vascular pole (VP) expressing only podocyte proteins $(34,35)$. Appropriate therapeutic methods are able to modulate the differentiation of renal progenitor cells towards podocytes $(36,37)$. MsPGN is considered an immunological disease, and angiotensin II receptor blockers (ARBs) are the primary treatment besides glucocorticoids $(38,39)$. ARBs are common agents in the clinic due to their ability to blockade the renin-angiotensin system (RAS) and modulate varieties of cytokines $(40,41)$. The use of ARBs in nephritis has been studied comprehensively; however, the direct cellular effects and mechanism of podocyte repopulation remain poorly understood.

The anti-thy1.1 nephritis model is typically considered the proper choice for imitating MsPGN in humans. Due to self-limited characteristics, the anti-thy1.1 nephritis model is optimal for studying recovery from MsPGN. The purpose of this study was to determine whether ARB medication attenuates experimental MsPGN by modulating the differentiation of renal progenitor cells towards podocytes and the related mechanisms.

\section{Methods}

The experimental protocol was approved by the Animal Ethics Review Committee of the Chinese People's Liberation Army (PLA) General Hospital according to the Chinese law for the protection of animals.

\section{Experimental anti-thy1.1 nephritis model and grouping}

Male Wistar rats weighing 180-200 g were acquired from Beijing HFK Bioscience Co., Ltd., and fed at the experimental animal center of the Chinese PLA General Hospital at $24 \pm 2{ }^{\circ} \mathrm{C}$ and $50 \% \pm 20 \%$ humidity. The rats were divided into the following three groups, with 24 rats within each group: (I) sham group, (II) anti-thy1.1 group (Thy1 group) and (III) anti-thy1.1 nephritis model + losartan group (losartan group) in which losartan was given by gavage at a dose of $50 \mathrm{mg} / \mathrm{kg}$ body weight per day. On day 0 , the rats in the sham group received $0.2 \mathrm{~mL}$ of $1 \times$ phosphatebuffered saline ( $\mathrm{pH} 7.4)$ by tail intravenous injection. The rats in the Thy-1 group were given an intravenous injection of monoclonal anti-thy1.1 antibody $(2.5 \mathrm{mg} / \mathrm{kg})$ produced by OX-7 hybridoma cells diluted in $1 \times$ phosphate-buffered saline $(\mathrm{pH} 7.4)$ and were administered vehicle from days 0 to 14 . The losartan group was injected with the same dose of anti-thy1.1 antibody as the Thy-1 group as above on day 0 and administered losartan potassium tablets (Merck Sharp \& Dohme Corp.) dissolved in deionized water on days 0-14. Blood and urine samples were collected on days 3, 7, and 14 after modeling. In each group, eight rats were sacrificed on days 3,7 , and 14 .

\section{Blood and urine samples}

Blood and urine samples were centrifuged, and the supernatants were kept at $-80^{\circ} \mathrm{C}$. All samples were taken to the Biochemistry Laboratory at the Chinese PLA General Hospital. Twenty-four-hour urinary protein quantification and serum creatinine were measured using an automated biochemical analyzer.

\section{Light microscopy}

Tissues from rat kidneys were preliminarily kept in 4\% paraformaldehyde and made into paraffin blocks. Sections (4 $\mu \mathrm{m})$ were cut, deparaffinized and stained with periodic acidSchiff (PAS). Two pathologists examined the glomerular injury of PAS staining sections for anti-thy1.1 nephritis.

\section{Western blot analysis}

Approximately $300 \mu \mathrm{L}$ of radioimmunoprecipitation assay buffer (RIPA lysis buffer, containing $150 \mathrm{mM} \mathrm{NaCl}, 1.0 \%$ NP-40 or $0.1 \%$ Triton X-100, $0.5 \%$ sodium deoxycholate, $0.1 \%$ sodium dodecyl sulfate, $50 \mathrm{mM}$ Tris- $\mathrm{HCl}$ at $\mathrm{pH} 8.0$, protease inhibitors) was added for a $\sim 5 \mathrm{mg}$ piece of tissue. The volumes of lysis buffer were determined based on the amount of tissue present. An electric homogenizer was used to homogenize the mixture above. Protein concentrations were calculated using a bicinchoninic acid (BCA) kit (Pierce, USA). The separated protein samples $(50 \mu \mathrm{L}$ per lane $)$ in $10 \%$ sodium dodecyl sulphate (SDS)-polyacrylamide gels were transferred to nitrocellulose membranes. We incubated the membranes overnight in $5 \%$ bovine serum albumin (BSA) and individual primary antibodies (namely, 
p57, WT-1, and CD24) at $4{ }^{\circ} \mathrm{C}$. The membranes were washed three times with $1 \times$ Tris-buffered saline with Tween 20, followed by incubation with secondary antibody for 1 hour. The electrophoresis results were detected by enhanced chemiluminescence (Amersham Biosciences, Little Chalfont, UK). The experimental procedures above were repeated at least three times.

\section{Immunofluorescence staining}

All immunofluorescence staining was performed on $4 \mu \mathrm{m}$ tissue frozen sections from rat renal biopsy specimens $\left(-80^{\circ} \mathrm{C}\right)$. According to the procedure, frozen sections were preliminarily fixed in $4 \%$ paraformaldehyde for 30 minutes, processed with $0.2 \%$ Triton for 5 minutes then $5 \%$ BSA for 45 minutes, and incubated with the appropriate primary antibodies overnight as described below. Secondary antibodies, Cyanine3 (Cy3) or/and fluorescein isothiocyanate (FITC) (Beyotime Biotechnology, Shanghai, China) were incubated the next day for 1 hour to visualize the immunofluorescence results.

\section{Single staining}

To ensure that the number of podocytes increased in the Losartan group, we performed single-label immunofluorescence for $\mathrm{p} 57$.

\section{Double immunofluorescence staining methods}

To observe the proliferative condition of glomeruli podocytes, double staining for WT-1 and Ki-67 was performed. To detect and measure the subset of renal epithelial progenitor cells that expressed only stem cell proteins and not podocyte markers, double immunofluorescence staining for CD24 with CD133 (42) and Synaptopodin was performed. To study the pathway by which renal progenitor cells differentiate into podocytes, double staining for $\mathrm{p}$-extracellular signal-regulated kinase (p-ERK) with CD133 was performed.

\section{Confocal microscopy}

Confocal microscopy was performed on $4 \mu \mathrm{m}$ sections of frozen renal tissues by using a confocal laser fluorescence microscope (FV1000-D) (OLYMPUS, Japan). Immunofluorescence results were collected and viewed using Olympus Fluoview v4.2b software.

\section{Primary antibodies}

The following antibodies were used: anti-CD133 pAb, antiSynaptopodin pAb, and anti-p57 Kip2 mAb (Abcam Ltd., Cambridge, UK); anti-CD24 mAb (SN3), anti-WT-1 mAb (F6), and anti-Ki-67 mAb (Santa Cruz Biotechnology, Santa Cruz, California); anti-phospho-p44/42 MAPK (ERK1/2) pAb (Thr202/Tyr204) (Cell Signaling Technology, Danvers, Massachusetts, USA).

\section{Quantification method and statistical analysis}

Positively stained podocytes were quantified in each rat using a combination of p57 and 4,6-diamino-2-phenyl indole (DAPI) staining at each time point. ImageJ software was used to measure the positive staining intensity of progenitors according to the ImageJ User Guide (version $1.50 \mathrm{~g}$ ). Thus, we analyzed the pixel density represented by the CD133, CD24, and Synaptopodin fluorescent staining in each individual glomerulus. Shown as a percentage of the glomerular tuft area, the value (namely, CD $133^{+} / \mathrm{CD} 24^{+}$and $\mathrm{CD} 24^{+} /$Synaptopodin $^{-}$) was determined by the pixel density representing the glomerular tuft area in each individual glomerulus. CD $133^{+} / \mathrm{pERK}^{+} \mathrm{PECs}$ were quantified as double positive $\mathrm{CD} 133^{+} \mathrm{pERK} \mathrm{K}^{+} \mathrm{PECs} /$ number of observed glomeruli (10 observed glomeruli each rat).

All values are reported as the mean \pm standard error of at least three independent experiments. For comparisons, one-way ANOVA was used, and post hoc analyses were performed with the least significant difference test. $\mathrm{P}<0.05$ was defined as a significant difference. SPSS software (version 23.0, IBM Corp., Chicago, IL, USA) was used to calculate statistical significance. GraphPad Prism software (version 7.0, San Diego, CA, USA) was used to evaluate the $50 \%$ inhibitory concentration $\left(\mathrm{IC}_{50}\right)$. Adobe Illustrator $\mathrm{CC}$ 2019 software was used to make illustrations.

\section{Results}

\section{Effect of losartan treatment on the anti-thy1.1 nephritis model as determined by proteinuria and pathological changes}

Twenty-four-hour urine for each rat was collected, and urine protein quantity was measured over 2 weeks. During the study on days 3,7 , and 14 , compared with the sham group, the Thy- 1 group and the losartan group presented significant persistent proteinuria $(\mathrm{P}<0.05)$. Additionally, compared with the Thy-1 group the losartan group 

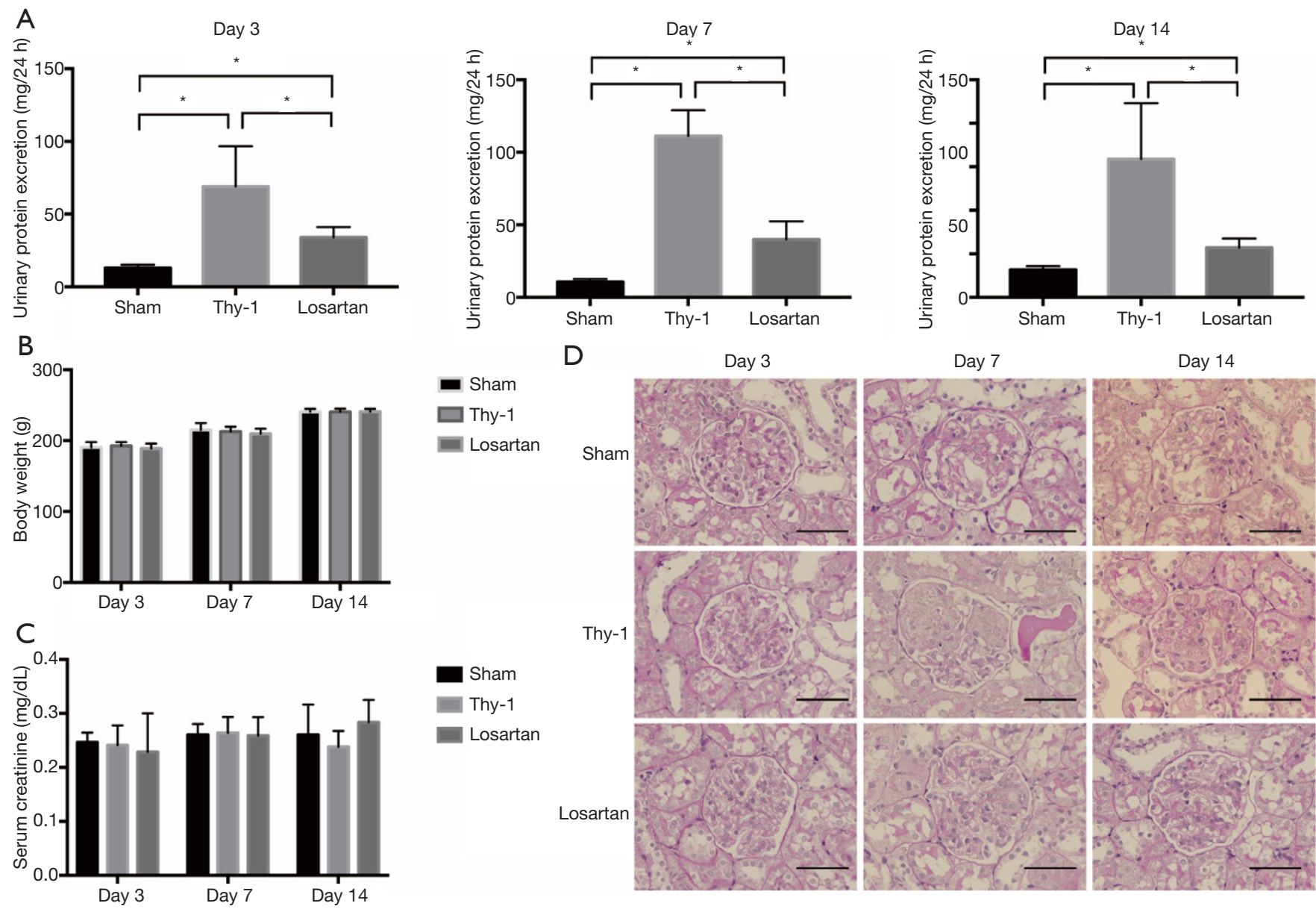

Figure 1 Effect of losartan treatment on anti-thy1.1 nephritis model according to proteinuria and pathological changes. (A) On the time point of days 3, 7 and 14, compared with Sham group, 24-h urinary protein excretion increased significantly in Thy-1 and Losartan groups after anti-thy1.1 antibody induced $\left(^{*}, \mathrm{P}<0.05\right)$. Compared with Thy-1 group, lower $24 \mathrm{~h}$ urinary protein was detected in losartan group $\left(^{*}\right.$, $\mathrm{P}<0.05$ ). (B,C) No significant difference among three groups was found in body weight and serum creatinine (P>0.05). (D) PAS staining was made and the results were shown as reported. More severe pathological changes were found in rats in Thy-1 group compared with Losartan group ( $\times 400$ original magnification). PAS, periodic acid-Schiff.

showed a significant reduction in 24-hour urine protein levels $(\mathrm{P}<0.05)$ (day 3: $12.84 \pm 2.24 \mathrm{mg}$ in the sham group, $68.95 \pm 27.72 \mathrm{mg}$ in the Thy-1 group and $33.91 \pm 7.10 \mathrm{mg}$ in the losartan group; day $7: 10.63 \pm 2.03 \mathrm{mg}$ in the sham group, $111.23 \pm 17.66 \mathrm{mg}$ in the Thy- 1 group and $40.00 \pm 12.46 \mathrm{mg}$ in the losartan group; day 14: $12.69 \pm 1.68 \mathrm{mg}$ in the sham group, $63.58 \pm 25.63 \mathrm{mg}$ in the Thy- 1 group and $22.88 \pm 4.15 \mathrm{mg}$ in the losartan group; Figure $1 \mathrm{~A}$ ). We examined the body weight of each rat over 2 weeks to assure the safety of losartan intake, and no significant difference among the sham, Thy-1 and losartan groups was found (Figure 1B), coinciding with the results reported by previous studies. We analyzed the serum creatinine level and found that there was no significance among the three groups (Figure 1C). Pathological changes were analyzed, and glomeruli injury was significantly attenuated in the losartan group compared with the Thy-1 group (Figure 1D).

\section{The number of podocytes increased in the anti-thy1.1 nephritis model following losartan treatment}

The number of podocytes was determined by quantifying the number of innate glomerular cells that stained for positive $\mathrm{p} 57$. On day 3 , the number of podocytes decreased significantly in the Thy-1 and losartan groups compared with the sham group (31.4 \pm 2.3 , sham group; $25.6 \pm 2.8$, Thy- 
1 group; $27.5 \pm 2.7$, losartan group; $\mathrm{P}<0.05)$. No difference in the number of podocytes was found between the Thy- 1 and losartan groups $(\mathrm{P}>0.05)$. On day 7 , with the development of the nephritis model, the severe depletion of podocytes persisted. Compared with the sham group, the Thy-1 group showed a significantly decreased number of podocytes $(31.8 \pm 1.9$ in the sham group vs. $11.6 \pm 2.3$ in the Thy-1 group; $\mathrm{P}<0.05)$. In contrast, the number of podocytes the losartan group was increased $(11.6 \pm 2.3$ in the Thy- 1 group vs. $23.5 \pm 4.4$ in the losartan group, $\mathrm{P}<0.05)$. On day 14 , similar to day 7 , significantly more $\mathrm{p} 57$-positive podocytes were observed in the sham group than in the Thy- 1 group $(30.3 \pm 3.3$ in the sham group vs. $5.9 \pm 2.2$ in the Thy- 1 group, $\mathrm{P}<0.05)$. The number of podocytes was much higher in the losartan group due to losartan treatment than in the Thy1 group (5.9 \pm 2.2 in the Thy- 1 group $v s .25 .9 \pm 1.7$ in the losartan group, $\mathrm{P}<0.05$; Figure $2 A$ ). These data showed that compared with no treatment, losartan treatment attenuated anti-thy1.1 nephritis due to the increased number of podocytes in nephritic rats.

P57 and WT-1 are both proteins specifically expressed by podocytes. To demonstrate the outcome above, we performed Western blot tests for $\mathrm{p} 57$ and WT-1 on day 7 . The protein expression of $\mathrm{p} 57$ and WT- 1 can be measured by computer densitometry and analyzed. Western blot analysis showed that compared with the sham group, the Thy- 1 and losartan groups expressed lower levels of p57 and WT-1 (p57: 0.20 \pm 0.048 sham group vs. $0.44 \pm 0.049$ Thy-1 group vs. $0.68 \pm 0.049$ losartan group, $\mathrm{P}<0.05$ ) (WT$1,0.15 \pm 0.011$ sham group $v s .0 .35 \pm 0.026$ Thy- 1 group $v$. $0.64 \pm 0.026$ losartan group, $\mathrm{P}<0.05)$. Compared with rats in the Thy-1 group, p57 and WT-1 protein expression increased significantly in the losartan group $(\mathrm{P}<0.05)$, consistent with the immunofluorescent results (Figure $2 B$ ). These data showed that after anti-thy1.1 antibody induction, increased protein expression of podocytes was associated with losartan treatment compared with untreated diseased rats.

\section{Podocyte proliferation was not present in the three groups}

As data shown above, the number of podocytes in the antithy1.1 nephritic model increased significantly in response to losartan treatment, and we sought to study how losartan treatment might lead to an increase in podocytes in rats with MsPGN. We performed double staining for WT-1 and $\mathrm{Ki}-67$ to determine whether an increased number of podocytes was associated with podocyte self-proliferation.
The results are shown in Figure 2C. On day 3, 7 and 14, no $\mathrm{Ki}-67^{+}$glomerular cells were found in the sham group. Many $\mathrm{Ki}-67^{+}$glomerular cells were detected in the Thy1 and losartan groups due to proliferative mesangial cells, but double staining for $\mathrm{WT}-1^{+} / \mathrm{Ki}-67^{+}$cells was rarely seen. Therefore, we determined that podocyte selfproliferation did not increase the number of podocytes. We sought to study PECs as progenitor cells since the increase in podocytes was not associated with podocyte selfproliferation.

\section{Regions containing renal progenitor and transitional state cells increased following losartan treatment}

To detect whether PEC regions containing potential progenitor cells, were increased with losartan treatment, we performed double staining for CD133 and CD24. Double positive staining for CD133 and CD24 was recognized as PEC regions containing progenitor cells and transitional state cells. We calculated the computer densitometry generated by ImageJ software to analyze the difference. Figure $3 A$, on day 3 after anti-thy 1.1 antibody induction, the $\mathrm{CD} 133^{+} / \mathrm{CD} 24^{+} \mathrm{PEC}$ region containing innate progenitors and transitional state cells was not significantly different between the Thy-1 group and the sham group $(\mathrm{P}>0.05)$, but a larger $\mathrm{CD} 133^{+} / \mathrm{CD} 24^{+}$region was detected in the losartan group $(\mathrm{P}<0.05)(5.868 \% \pm 0.629 \%$ in the sham group, $6.813 \% \pm 0.760 \%$ in the Thy- 1 group and $11.952 \% \pm 1.957 \% /$ glomerular cross section in the losartan group). On day 7 and 14 , an enlarged CD $133^{+} / \mathrm{CD} 24^{+} \mathrm{PEC}$ region was found in the Thy- 1 and losartan groups compared with the sham group $(\mathrm{P}<0.05)$ (day $7: 5.606 \% \pm 1.595 \% /$ glomerular cross section in the sham group, $11.054 \% \pm 1.742 \% /$ glomerular cross section in the Thy-1 group and $14.035 \% \pm 1.883 \% /$ glomerular cross section in the losartan group; day 14: $5.162 \% \pm 1.078 \% /$ glomerular cross section in the sham group, $8.710 \% \pm 1.802 \% /$ glomerular cross section in the Thy-1 group and $12.065 \% \pm 2.122 \% /$ glomerular cross section in the losartan group), and the region was detected in the losartan group was larger than that detected in the Thy-1 group $(\mathrm{P}<0.05)$.

As shown in Figure 3B, we also analyzed the day 7 CD24 Western blot results. CD24 protein expression was higher in the Thy- 1 and losartan groups than in the sham group $(0.050 \pm 0.003$ in the sham group vs. $0.060 \pm 0.006$ in the Thy1 group and $0.096 \pm 0.015$ in the losartan group, $\mathrm{P}<0.05$ ), and CD24 expression increased significantly in the losartan group after losartan treatment compared with the Thy-1 


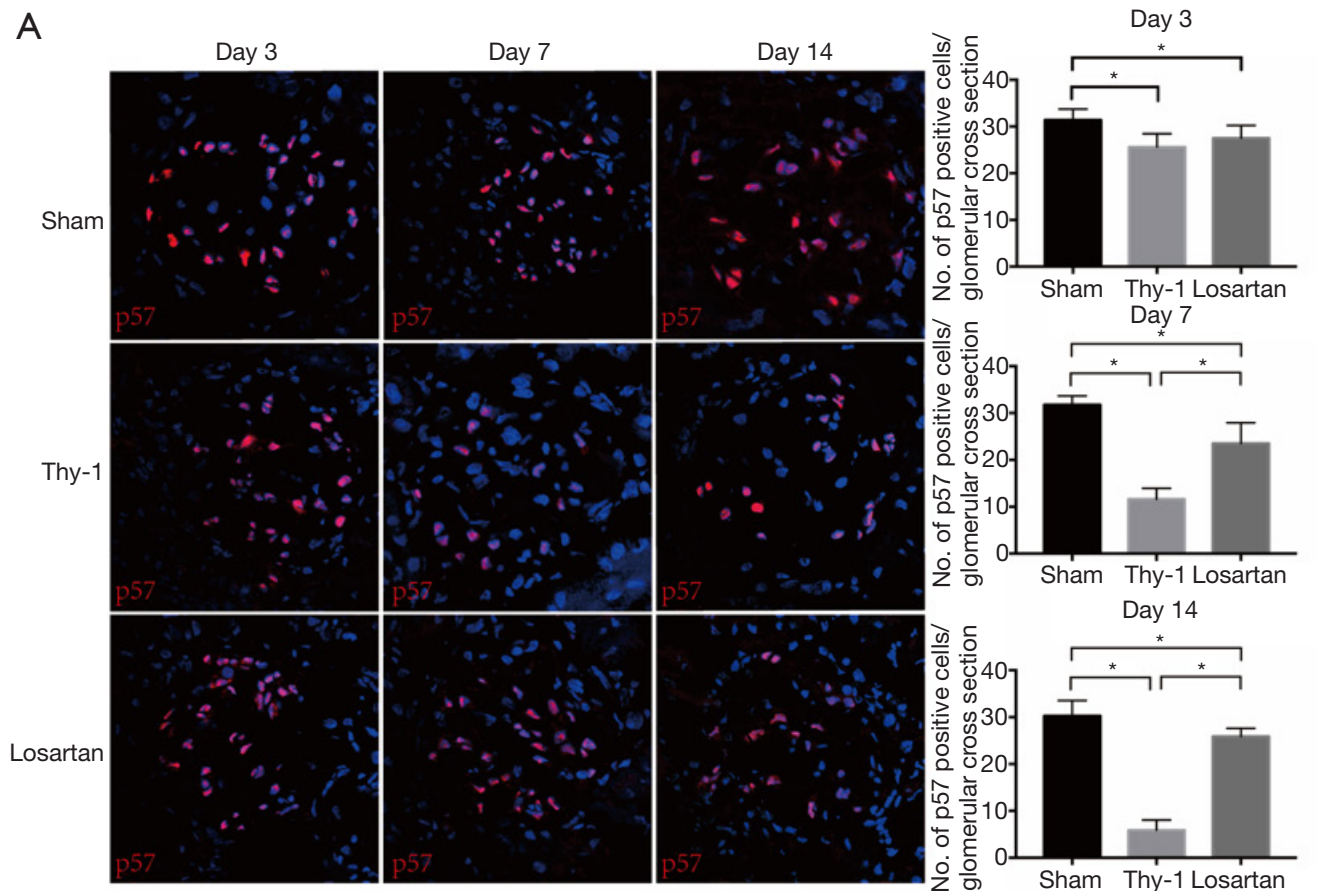

B

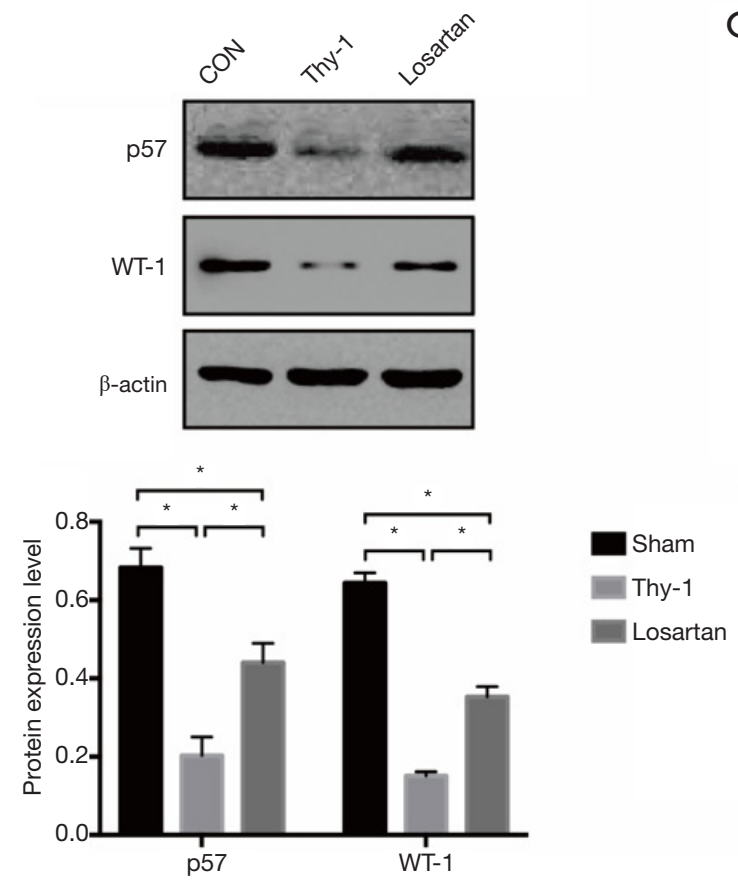

C

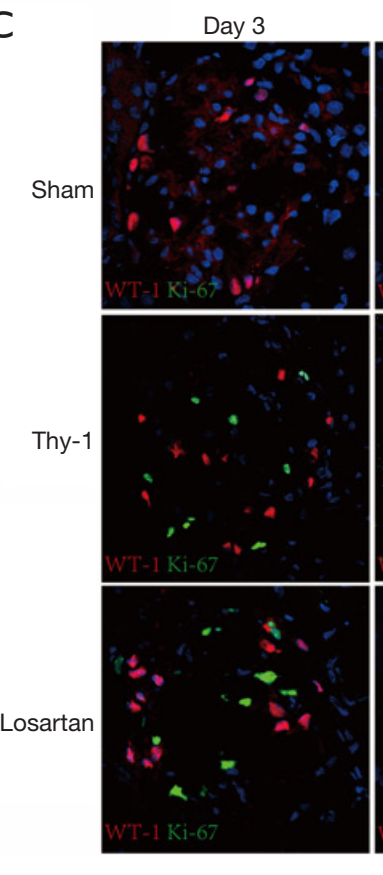

Day 7

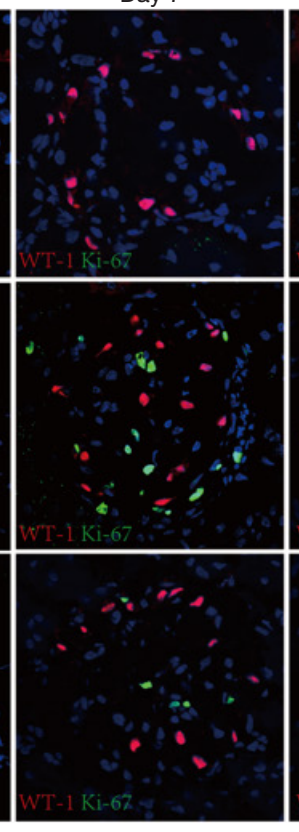

Day 14

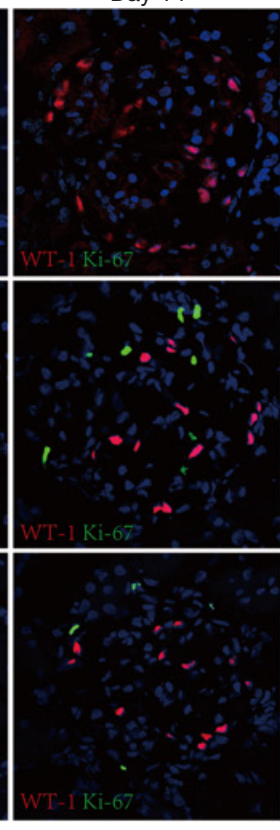

Figure 2 Podocyte number increased in anti-thy1.1 nephritis model following losartan treatment and podocytes proliferation did not present among three groups. (A) On day 3, compared with Sham group, podocyte number (red, p5 $7^{+}$cells) of Thy-1 and Losartan group decreased significantly after anti-thy1.1 antibody injected $(*, \mathrm{P}<0.05)$. There is no difference between Thy-1 and Losartan group in podocyte number $(\mathrm{P}>0.05)$. On days 7 and 14, compared with Sham group, lower number of podocytes in Thy-1 and Losartan group was found $\left(^{*}, \mathrm{P}<0.05\right)$. And after losartan administrated, podocyte number of Losartan group increased significantly, compared with Thy- 1 group ${ }^{*}, \mathrm{P}<0.05, \times 400$ original magnification). (B) On day 7 , p57 and WT-1 protein expression level in Thy-1 and Losartan group was significantly lower than Sham group $\left(^{*}, \mathrm{P}<0.05\right)$. And compared with Thy-1 group, the protein level increased significantly in Losartan group (*, $\mathrm{P}<0.05)$. (C) During 2 weeks, no proliferative cells (green, Ki-67 ${ }^{+}$cells) was detected in Sham group at $\times 400$ original magnification. And $\mathrm{Ki}-67^{+}$positive cells were restricted to proliferative mesangial cells in Thy-1 and Losartan groups. No proliferative podocytes (red, WT-1 $1^{+} /$green, $\mathrm{Ki}-67^{+}$) was found in the three groups in the studies. 
A

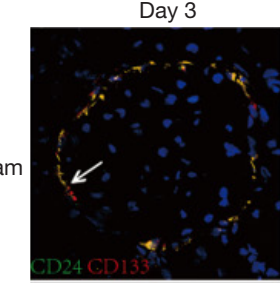

Thy-1
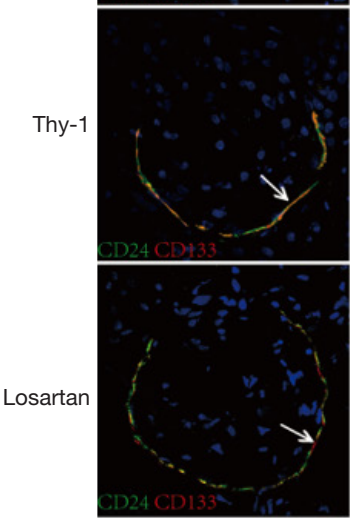

C
Day 7
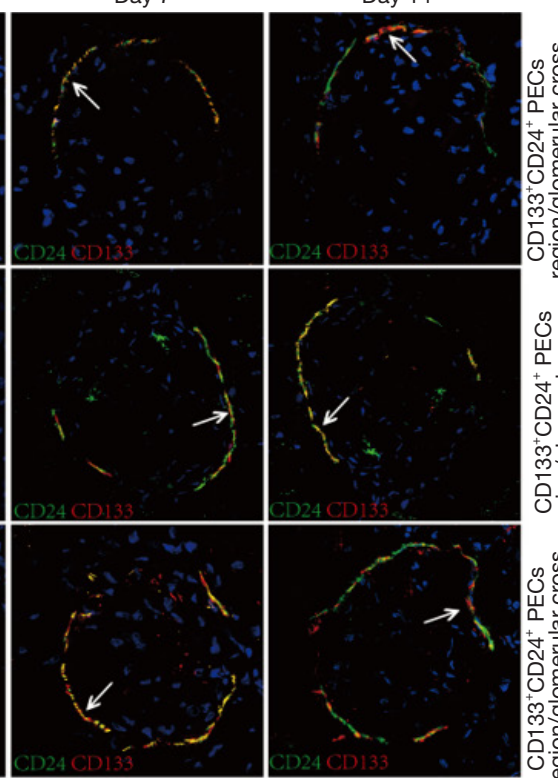
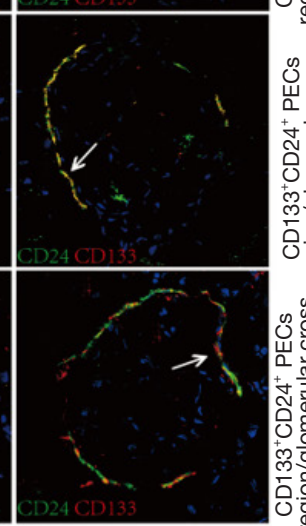

Day 7
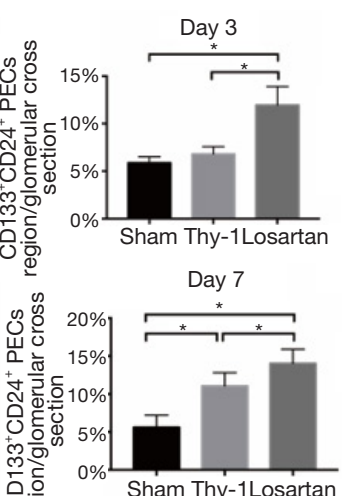

Sham Thy-1Losartan

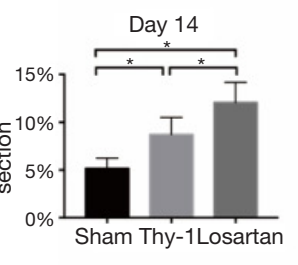

B
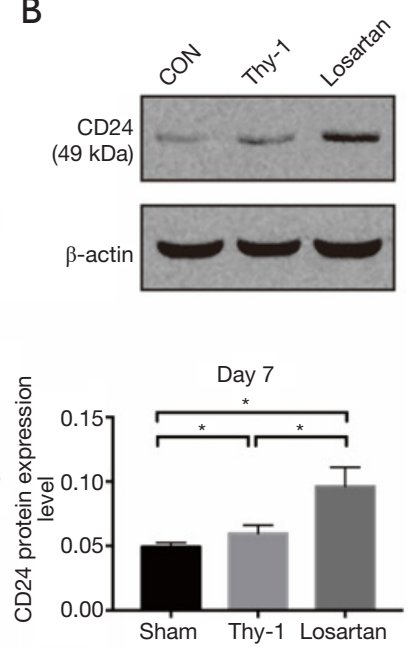

Day 14

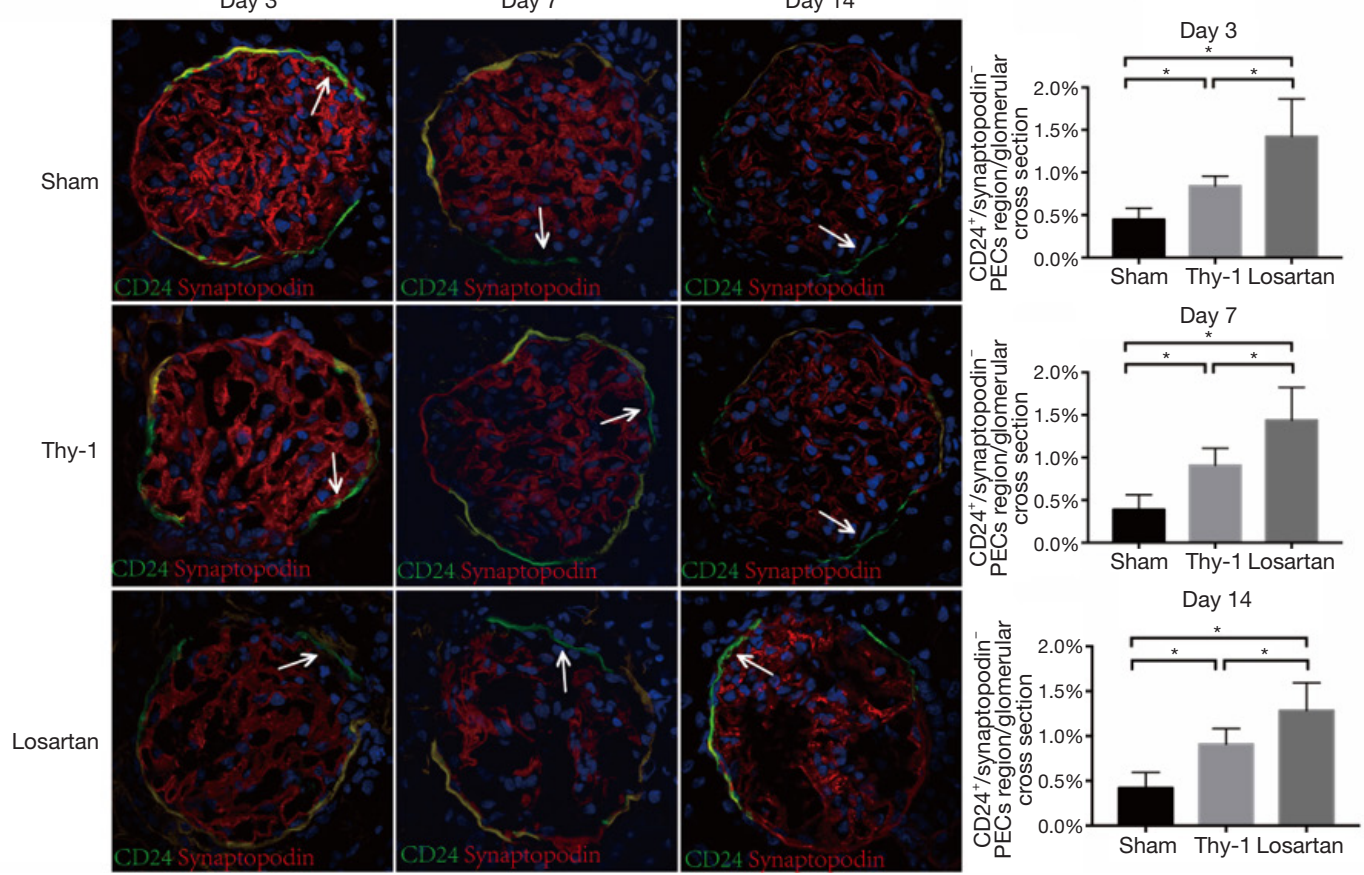

Figure 3 Regions of progenitors along PECs expanded following losartan treatment. (A) Positive regions of renal progenitor and transitional state cells increased following losartan treatment. ImageJ software was used to generate computer densitometry. On day 3, compared with Sham group, no significant difference was found in Thy-1 group $(\mathrm{P}>0.05)$, but higher $\mathrm{CD} 133^{+} \mathrm{CD} 24^{+} \mathrm{PECs}$ region (arrowheads) per glomerular cross section was detected in Losartan group $\left({ }^{*}, \mathrm{P}<0.05, \times 400\right.$ original magnification). On days 7 and 14 , in contrast, CD133 ${ }^{+} \mathrm{CD} 24^{+} \mathrm{PECs}$ staining region in Thy1 and Losartan group was higher than Sham group. Compared with Thy- 1 group, larger CD $133^{+} \mathrm{CD} 24^{+}$PECs region was found in Losartan group $\left.{ }^{*}, \mathrm{P}<0.05\right)$. (B) Specific stem cell marker CD24 was chosen to perform western blot test on day 7. Compared with Sham group, CD24 protein expression level in Thy-1 and Losartan group was higher $\left({ }^{*}, \mathrm{P}<0.05\right)$. And Losartan group expressed more CD24 protein than Thy-1 group $\left(^{*}\right.$, $\mathrm{P}<0.05)$. (C) Renal progenitor cells region along PECs extended due to losartan treatment. As reported, renal progenitor PECs expressed stem cell protein without podocytes markers. So CD24 ${ }^{+}$synapotopodin ${ }^{-}$was performed to locate the renal progenitor PECs (arrowheads). On days 3, 7 and 14 , compared with Sham group, higher CD24 $4^{+}$synaptopodin ${ }^{-}$PECs region was detected in Thy- 1 and Losartan group $\left(^{*}, \mathrm{P}<0.05, \times 400\right.$ original magnification). And in contrast, CD24 $4^{+}$synaptopodin ${ }^{-}$PECs region in Losartan group was higher than Thy-1 group $\left({ }^{*}, \mathrm{P}<0.05\right)$. PEC, parietal epithelial cell. 
group $(\mathrm{P}<0.05)$.

\section{The area of renal progenitor cells in the PEC regions extended in response to losartan treatment}

According to previous studies, renal progenitor cells are defined as renal PECs expressing only stem cell proteins without podocyte markers. CD24 $4^{+}$Synaptopodin- staining was performed to locate renal innate progenitors. In this study, we found that the area of renal progenitor cells in the PEC region was significantly increased in the Thy- 1 and losartan groups compared with the sham group $(\mathrm{P}<0.05)$, and the range of $\mathrm{CD}_{2} 4^{+} /$Synaptopodin ${ }^{-}$was significantly increased in the losartan group compared with the Thy-1 group $(\mathrm{P}<0.05)($ day $3: 0.45 \% \pm 0.13 \% /$ glomerular cross section in the sham group, $0.84 \% \pm 0.12 \% /$ glomerular cross section in the Thy- 1 group and $1.42 \% \pm 0.44 \% /$ glomerular cross section in the losartan group; day 7 : $0.39 \% \pm 0.17 \% /$ glomerular cross section in the sham group, $0.91 \% \pm 0.20 \% /$ glomerular cross section in the Thy- 1 group and $1.44 \% \pm 0.39 \% /$ glomerular cross section in the losartan group; day $14: 0.42 \% \pm 0.17 \% /$ glomerular cross section in the sham group, $0.91 \% \pm 0.18 \% /$ glomerular cross section in the Thy- 1 group and $1.28 \% \pm 0.31 \% /$ glomerular cross section in the losartan group; Figure 3C).

\section{P-ERK1/2 signaling patbway was augmented in losartan- treated rats with experimental MsPGN}

The p-ERK signaling pathway is involved in the regulation of the growth, division, development, differentiation and proliferation of several epithelial cells (43). We performed double immunofluorescent staining for CD133 and p-ERK1/2 to detect the ERK pathway. Double positive

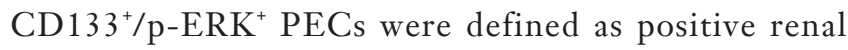
PECs. In this study, we found that the p-ERK1/2 signaling pathway participated in the differentiation of renal progenitor cells into podocytes. Additionally, the p-ERK1/2 pathway can be regulated by losartan administration (day $3: 0.063 \pm 0.052$ in the sham group, $0.288 \pm 0.084$ in the Thy- 1 group and $0.438 \pm 0.160$ in the losartan group; day 7: $0.050 \pm 0.054$ in the sham group, $0.225 \pm 0.089$ in the Thy- 1 group and $0.600 \pm 0.185$ in the losartan group; day 14 : $0.063 \pm 0.052$ in the sham group, $0.200 \pm 0.093$ in the Thy- 1 group and $0.475 \pm 0.183$ in the losartan group; Figure 4).

\section{Discussion}

MsPGN is accepted as immunocomplex-induced nephritis, and pathological studies have also confirmed that MsPGN is mostly caused by systemic immune problems $(44,45)$. ARBs, as safe and effective medications, are extensively used by MsPGN patients to treat proteinuria. The benefits of ARBs for MsPGN patients with proteinuria have been described adequately in both basic and clinical studies. The number of podocytes increased significantly following $\mathrm{ARB}$ treatment for MsPGN in both animals and humans, as previously reported. However, in contrast to corticosteroids, ARBs show insufficient effects on immune disorders and limited ability to prevent podocytes from undergoing apoptosis, which prompted us to focus on its direct cellular effect. In this study, we demonstrate that the depletion of podocytes occurs rapidly in rats with experimental MsPGN after anti-thy1.1 antibody induction, and the number of podocytes can be increased by losartan administration due to the significantly increased progenitor cell domain.

The vascular barrier formed by podocytes is functionally critical to the nephron. As highly specialized and terminally differentiated epithelial cells, podocytes lack the ability to self-repopulate $(46,47)$. To our knowledge, as long as the depletion of podocytes is moderate, glomeruli restitution is possible. However, if podocyte loss becomes severe and the proportion of involved glomeruli increases, globally sclerotic and nonfiltering glomeruli can be found, corresponding with persistent proteinuria and a measurable reduction in the glomerular filtration rate $(3,14)$. Therefore, podocyte injury is recognized as the initiating and primary factor in the development of various types of nephritis (15). During MsPGN development, persistent proteinuria indicates severely increased depletion of podocytes. How might losartan help to repair glomeruli in MsPGN? A rat model of MsPGN was used in this study. The experimental rat model induced with the anti-thy1.1 antibody is the typical nephritic model for human MsPGN. As reported before, due to its self-limited characteristics, this model is optimal for studying recovery from MsPGN and whether the proliferation of renal progenitor cells helps to replace damaged podocytes.

First, we selected p57, which is restricted to podocytes in glomeruli, to determine the number of podocytes. Throughout the progression of anti-thy1.1 nephritis, we analyzed the number of podocytes on days 3, 7, and 14 . On day 3 after disease induction, the number of podocytes started to decline significantly and proteinuria was detected. With the development of anti-thy 1.1 nephritis, the depletion of podocytes became the most severe on day 7 , consistent with relevant pathological manifestations and marked proteinuria. On day 14 , the number of podocytes 

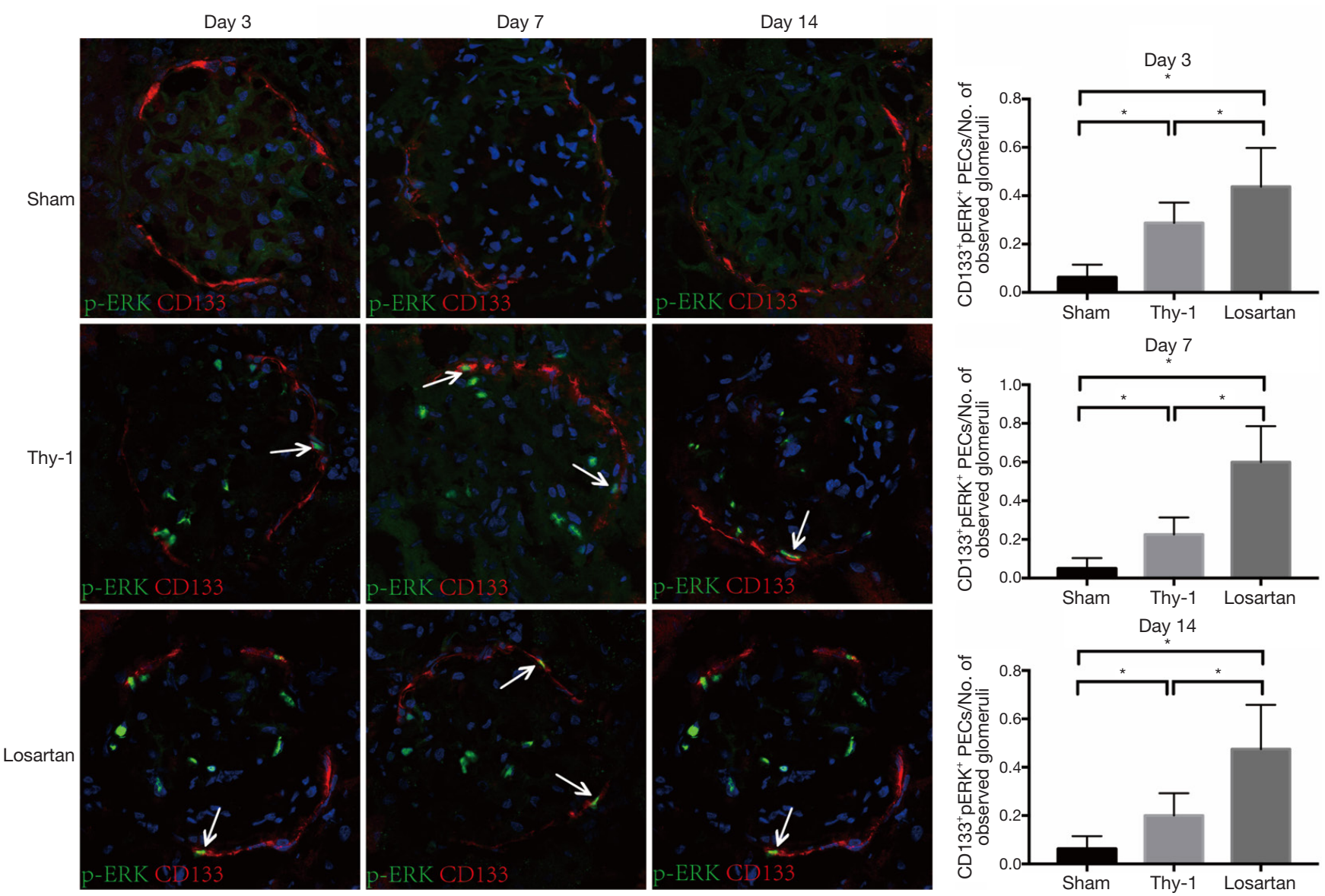

Figure 4 P-ERK1/2 signal pathway augmented in losartan-treated rats with experimental MsPGN. P-ERK signal pathway was involved in multiple cellular activities, especially differentiation and proliferation. In the study of CD133/p-ERK double staining, we found that on days 3 , 7 and 14, compared with Sham group, number of CD133 ${ }^{+}$-ERK ${ }^{+}$PECs (arrowheads) per glomerular cross section in Thy-1 and Losartan groups increased significantly $\left(^{*}, \mathrm{P}<0.05, \times 400\right.$ original magnification). And double positive number of CD133 ${ }^{+}$p-ERK ${ }^{+} \mathrm{PECs}$ in Losartan group was more than Thy-1 group ( $\left.{ }^{*}, \mathrm{P}<0.05\right)$. MsPGN, mesangial proliferative glomerulonephritis; PEC, parietal epithelial cell.

was partially restored, but glomerular scarring remained, and proteinuria persisted. A significantly increased number of podocytes was found in the losartan group compared with the Thy- 1 group. Moreover, an increase in podocytes directly correlated with reduced proteinuria, as reported in previous pathological studies.

WT-1/Ki-67 double staining was performed to demonstrate whether the increased number of podocytes was due to self-proliferation. In this study, we found many proliferative cells along the intraglomerular mesangial region in the Thy-1 and losartan groups, as expected. However, $\mathrm{WT}-1^{+} / \mathrm{Ki}-67^{+}$cells were rarely found in the three groups, indicating that podocyte proliferation was limited. As terminally differentiated epithelial cells, podocytes cannot adequately replace any decrease in cell number due to the lack of the necessary cell cycle machinery. Therefore, we evaluated the effect of podocyte repopulation on cellular effects, especially on renal progenitor cells.

To describe the proliferation of progenitor cells, CD133/ CD24 and CD24/Synaptopodin double staining were performed. Innate renal progenitor cells were defined as cells that only expressed stem cell protein and not podocyte markers and that resided along BC. CD $133^{+} / \mathrm{CD} 24^{+}$ staining represented the area containing progenitor cells and transitional state cells, while CD24 $4^{+}$/Synaptopodin staining labeled renal progenitor cells. In this study, the $\mathrm{CD} 133^{+} / \mathrm{CD} 24^{+}$area (staining along BC) was significantly augmented in the losartan-treated group compared with the untreated Thy- 1 group. Likewise, a more enlarged CD $24^{+} /$ Synaptopodin ${ }^{-}$area was detected. Among the hierarchical 
subpopulations of PECs, renal progenitor cells express stem cell markers, and transitional state cells express both stem cells and podocyte markers, which then terminally differentiate into the podocytes. According to the study led by Shankland (31), only stem cell marker ${ }^{+}$podocyte marker ${ }^{-}$ PECs displayed the potential to regenerate podocytes and to improve glomerular injury, and stem cell marker ${ }^{+} /$ podocyte marker ${ }^{+}$PECs were not able to improve kidney injury and rarely generated podocytes due to their limited engraftment capacity and lack of self-renewal potential $(3,15,16,48)$. In the CD24/Synaptopodin staining study, significantly augmented PECs expressing stem cell markers, namely, renal progenitor cells, were found in the losartan group compared with the Thy-1 group. This finding indicated that losartan, as an ARB, is potentially helpful in regulating the differentiation of renal progenitor cells into podocytes to attenuate anti-thy1.1 nephritis.

We did not discover the precise mechanism that regulates the differentiation of progenitor cells into podocytes due to complex and not one-fit-all signal pathways. Our study focused on the p-ERK signaling pathway because ERK is a member of the mitogen-activated protein kinase (MAPK) family and is involved in the regulation of the growth, division, development, differentiation and proliferation of several epithelial cells. We found that several PECs along BC co-expressed CD $133^{+} / \mathrm{p}-\mathrm{ERK}^{+}$in the Thy-1 group. After losartan administration, additional CD $133^{+} / \mathrm{p}-\mathrm{ERK}^{+}$ PECs were detected. All the results suggested that the p-ERK signaling pathway participated in PEC progenitor cell differentiation into podocytes and that losartan was able to regulate this pathway. However, this research method was limited, and we could not prove that the p-ERK pathway primarily underlied the effect.

\section{Conclusions}

Finally, in summary, losartan could attenuate the anti-thy1.1 nephritic rat model by increasing the number of podocytes, which was correlated with reduced proteinuria and the alleviation of pathological changes. We detected an increase in progenitor cells after losartan administration, which was important in podocyte repopulation. The p-ERK1/2 signaling pathway participated in the differentiation of renal progenitor PECs into podocytes, which will be important for the treatment of kidney disease in the future. We considered renal progenitor cells, namely, PECs, to be another important factor for saving injured kidneys.

\section{Acknowledgments}

Funding: All equipment and drugs mentioned in this paper were funded by National Natural Science Foundation of China (No. 81330019).

\section{Footnote}

Conflicts of Interest: The authors have no conflicts of interest to declare.

Ethical Statement: The authors are accountable for all aspects of the work in ensuring that questions related to the accuracy or integrity of any part of the work are appropriately investigated and resolved. The experimental protocol was approved by the Animal Ethics Review Committee of the Chinese People's Liberation Army (PLA) General Hospital according to the Chinese law for the protection of animals (No. 2017-X14-60).

Open Access Statement: This is an Open Access article distributed in accordance with the Creative Commons Attribution-NonCommercial-NoDerivs 4.0 International License (CC BY-NC-ND 4.0), which permits the noncommercial replication and distribution of the article with the strict proviso that no changes or edits are made and the original work is properly cited (including links to both the formal publication through the relevant DOI and the license). See: https://creativecommons.org/licenses/by-nc-nd/4.0/.

\section{References}

1. Brück K, Stel VS, Gambaro G, et al. CKD Prevalence Varies across the European General Population. J Am Soc Nephrol 2016;27:2135-47.

2. Chen TK, Knicely DH, Grams ME. Chronic Kidney Disease Diagnosis and Management: A Review. JAMA 2019;322:1294-304.

3. Trimarchi H, Barratt J, Cattran DC, et al. Oxford Classification of IgA nephropathy 2016: an update from the IgA Nephropathy Classification Working Group. Kidney Int 2017;91:1014-21.

4. Arias LF, Taborda-Murillo A. Mesangial proliferative glomerulonephritis: A glomerular disease or a nonspecific morphological change? Nephrology (Carlton) 2017;22:575.

5. Lai KN, Tang SC, Schena FP, et al. IgA nephropathy. Nat Rev Dis Primers 2016;2:16001. 
6. Calizo RC, Bhattacharya S, van Hasselt JGC, et al. Disruption of podocyte cytoskeletal biomechanics by dasatinib leads to nephrotoxicity. Nat Commun 2019;10:2061.

7. Schell C, Huber TB. The Evolving Complexity of the Podocyte Cytoskeleton. J Am Soc Nephrol 2017;28:3166-74.

8. Nihalani D, Solanki AK, Arif E, et al. Disruption of the exocyst induces podocyte loss and dysfunction. J Biol Chem 2019;294:10104-19.

9. Trimarchi H, Coppo R. Podocytopathy in the mesangial proliferative immuno-globulin A nephropathy: new insights into the mechanisms of damage and progression. Nephrol Dial Transplant 2019;34:1280-5.

10. Allison SJ. Podocyte biology: The podocyte adhesome. Nat Rev Nephrol 2017;13:445.

11. Inoue K, Gan G, Ciarleglio M, et al. Podocyte histone deacetylase activity regulates murine and human glomerular diseases. J Clin Invest 2019;129:1295-313.

12. Nagata $M$. Podocyte injury and its consequences. Kidney Int 2016;89:1221-30.

13. Qi YY, Zhou XJ, Cheng FJ, et al. Increased autophagy is cytoprotective against podocyte injury induced by antibody and interferon-alpha in lupus nephritis. Ann Rheum Dis 2018;77:1799-809.

14. Saleem MA. Molecular stratification of idiopathic nephrotic syndrome. Nat Rev Nephrol 2019;15:750-65.

15. Miyazaki Y, Shimizu A, Ichikawa I, et al. Mice are unable to endogenously regenerate podocytes during the repair of immunotoxin-induced glomerular injury. Nephrol Dial Transplant 2014;29:1005-12.

16. Grahammer F, Wanner N, Huber TB. Podocyte regeneration: who can become a podocyte? Am J Pathol 2013;183:333-5.

17. Wang M. Lipids mediate podocyte damage. Nat Rev Nephrol 2019;15:594.

18. Andeen NK, Nguyen TQ, Steegh F, et al. The phenotypes of podocytes and parietal epithelial cells may overlap in diabetic nephropathy. Kidney Int 2015;88:1099-107.

19. Lasagni L, Angelotti ML, Ronconi E, et al. Podocyte Regeneration Driven by Renal Progenitors Determines Glomerular Disease Re-mission and Can Be Pharmacologically Enhanced. Stem Cell Reports 2015;5:248-63.

20. Kaverina NV, Eng DG, Schneider RR, et al. Partial podocyte replenishment in ex-perimental FSGS derives from nonpodocyte sources. Am J Physiol Renal Physiol 2016;310:F1397-413.
21. Berger K, Schulte K, Boor P, et al. The regenerative potential of parietal epithelial cells in adult mice. J Am Soc Nephrol 2014;25:693-705.

22. Shankland SJ, Pippin JW, Duffield JS. Progenitor cells and podocyte regeneration. Semin Nephrol 2014;34:418-28.

23. Romagnani P, Lasagni L, Remuzzi G. Renal progenitors: an evolutionary conserved strategy for kidney regeneration. Nat Rev Nephrol 2013;9:137-46.

24. Lim BJ, Yang JW, Do WS, et al. Pathogenesis of Focal Segmental Glomerulosclerosis. J Pathol Transl Med 2016;50:405-10.

25. Endlich N, Kliewe F, Kindt F, et al. The transcription factor Dach1 is essential for podocyte function. J Cell Mol Med 2018;22:2656-69.

26. Roeder SS, Stefanska A, Eng DG, et al. Changes in glomerular parietal epithelial cells in mouse kidneys with advanced age. Am J Physiol Renal Physiol 2015;309:F164-78.

27. Manonelles A, Guiteras R, Melilli E, et al. The Presence of Urinary Renal Progenitor Cells in Stable Kidney Transplant Recipients Anticipates Allograft Deterioration. Front Physiol 2018;9:1412.

28. Kietzmann L, Guhr SS, Meyer TN, et al. MicroRNA193a Regulates the Transdifferentiation of Human Parietal Epithelial Cells toward a Podocyte Phenotype. J Am Soc Nephrol 2015;26:1389-401.

29. Moeller MJ, Tharaux PL. Cellular regeneration of podocytes from parietal cells: the debate is still open. Kidney Int 2019;96:542-44.

30. Shankland SJ, Freedman BS, Pippin JW. Can podocytes be regenerated in adults? Curr Opin Nephrol Hypertens 2017;26:154-64.

31. Shankland SJ, Smeets B, Pippin JW, et al. The emergence of the glomerular parietal epithelial cell. Nat Rev Nephrol 2014;10:158-73.

32. Kaverina NV, Eng DG, Freedman BS, et al. Dual lineage tracing shows that glomerular parietal epithelial cells can transdifferentiate toward the adult podocyte fate. Kidney Int 2019;96:597-611.

33. Hayashi A, Okamoto T, Yamazaki T, et al. CD44-Positive Glomerular Parietal Epithelial Cells in a Mouse Model of Calcineurin Inhibitors-Induced Nephrotoxicity. Nephron 2019;142:71-81.

34. Kuppe C, Leuchtle K, Wagner A, et al. Novel parietal epithelial cell subpopulations contribute to focal segmental glomerulosclerosis and glomerular tip lesions. Kidney Int 2019;96:80-93.

35. Eng DG, Sunseri MW, Kaverina NV, et al. Glomerular parietal epithelial cells contribute to adult podocyte 
Page 12 of 12

regeneration in experimental focal segmental glomerulosclerosis. Kidney Int 2015;88:999-1012.

36. D'Agati VD, Shankland SJ. Recognizing diversity in parietal epithelial cells. Kidney Int 2019;96:16-9.

37. Zhang J, Pippin JW, Krofft RD, et al. Podocyte repopulation by renal progenitor cells following glucocorticoids treatment in experimental FSGS. Am J Physiol Renal Physiol 2013;304:F1375-89.

38. Pozzi C. Treatment of IgA nephropathy. J Nephrol 2016;29:21-5.

39. Holdsworth SR, Kitching AR. Progress in mechanisms and therapy for immunological kidney disease. Nat Rev Nephrol 2018;14:76-78.

40. Rauen T, Eitner F, Fitzner C, et al. Intensive Supportive Care plus Immunosuppression in IgA Nephropathy. N Engl J Med 2015;373:2225-36.

41. Xiao C, Zhou Q, Li X, et al. Losartan and Dexamethasone may inhibit chemotaxis to reduce the infiltration of Th22 cells in IgA nephropathy. Int Immunopharmacol 2017;42:203-8.

42. Ehsani E, Shekarchian S, Baharvand H, et al. Improved differentiation of human enriched CD133+CD24+ renal

Cite this article as: $\mathrm{Wu} \mathrm{D}$, Bai J, Cui S, Fu B, Yin Z, Cai G, Chen X. Renal progenitor cells modulated by angiotensin II receptor blocker (ARB) medication and differentiation towards podocytes in anti-thy1.1 nephritis. Ann Transl Med 2020;8(6):355. doi: 10.21037/atm.2020.02.58

\section{Wu et al. Renal progenitor cells modulated by ARB medication}

progenitor cells derived from embryonic stem cell with embryonic mouse kidney-derived mesenchymal stem cells co-culture. Differentiation 2019;109:1-8.

43. Kurtzeborn K, Kwon HN, Kuure S. MAPK/ERK Signaling in Regulation of Renal Differentiation. Int J Mol Sci 2019;20:1779.

44. Lu Y, Mei Y, Chen L, et al. The role of transcriptional factor D-site-binding protein in circadian CCL2 gene expression in anti-Thy1 nephritis. Cell Mol Immunol 2019;16:735-45.

45. Liu P, Lassén E, Nair V, et al. Transcriptomic and Proteomic Profiling Provides Insight into Mesangial Cell Function in IgA Nephropathy. J Am Soc Nephrol 2017;28:2961-72.

46. Liu M, Liang K, Zhen J, et al. Sirt6 deficiency exacerbates podocyte injury and proteinuria through targeting Notch signaling. Nat Commun 2017;8:413.

47. Assady S, Wanner N, Skorecki KL, et al. New Insights into Podocyte Biology in Glomerular Health and Disease. J Am Soc Nephrol 2017;28:1707-15.

48. Puelles VG, Moeller MJ. Postnatal podocyte gain: Is the jury still out? Semin Cell Dev Biol 2019;91:147-52. 